\title{
Atrial Fibrillation: Risk Assessment
}

\author{
Colbert Perez MD, Alejandro Perez-Verdia MD
}

Atrial fibrillation is the most common arrhythmia in clinical practice and accounts for significant health care costs. An estimated 2.2 million people in the US have this arrhythmia, and the incidence increases annually by $1.3 \%$ to $18 \%$. One important consideration for patients with atrial fibrillation is the risk of thromboembolic events. However, treatment for stroke prevention often presents difficult decisions for both patients and physicians.

Anticoagulation in patients with atrial fibrillation reduces the risk of thromboembolic events, but each patient's risk is different. The easiest and best known risk calculator to evaluate a patient's risk is the $\mathrm{CHADS}_{2}$ score which can predict the risk of stroke for the following year (Table 1). ${ }^{2}$ This score quickly replaced the Atrial Fibrillation Investigators criteria and Stroke Prevention in Atrial Fibrillation Investigators criteria scores since it provides more accurate predictions and is simple to calculate and remember. The more recent $\mathrm{CHA}_{2} \mathrm{DS}_{2}$-VASc includes three additional risk factors and doubles the risk for age (Table 2). This provides better risk stratification for patients considered at low risk based on their $\mathrm{CHADS}_{2}$ score $\left(\mathrm{CHADS}_{2}<1\right)$, a group in which $0.84 \%-3.2 \%$ of the patients have a thromboembolic event each year. ${ }^{3}$ The European Society of Cardiology guidelines now recommend the use of $\mathrm{CHA}_{2} \mathrm{DS}_{2}$-VASc score system instead of the $\mathrm{CHADS}_{2}$. As a result of using the $\mathrm{CHA}_{2} \mathrm{DS}_{2}$-VASc and identifying a higher risk in same patients, more patients will be treated for thromboembolic prevention (Table 3 ).

Cooresponding Author: Colbert Perez MD Author Contact Information: Colbert.perez@ttuhsc.edu DOI: $10.12746 /$ swrccc2014.0206.080
Table 1. $\mathrm{CHADS}_{2}$ Score

\begin{tabular}{|l|l|}
\hline \multicolumn{1}{|c|}{ CHADS $_{2}$} & Score \\
\hline CHF & 1 \\
\hline Hypertension & 1 \\
\hline Age $>75$ & 1 \\
\hline Diabetes & 1 \\
\hline Stroke or TIA & 2 \\
\hline
\end{tabular}

Table 2. $C H A_{2} D S_{2}-V A S_{C}$ Score

\begin{tabular}{|l|l|}
\hline \multicolumn{1}{|c|}{$\mathbf{C H A}_{2} \mathbf{D S}_{2}-\mathbf{V A S}_{\mathbf{c}}$} & Score \\
\hline CHF & 1 \\
\hline Hypertension & 1 \\
\hline Age $>75$ & 2 \\
\hline Diabetes & 1 \\
\hline Stroke or TIA & 2 \\
\hline Vascular Disease & 1 \\
\hline Age 65-74 & 1 \\
\hline Female & 1 \\
\hline
\end{tabular}

Table 3. $C H A_{2} D S_{2}-V A S_{C}$ Stroke Rate

\begin{tabular}{|l|c|}
\hline Score & Adjusted Yearly Stroke Rate \\
\hline 0 & $6.2 \%$ \\
\hline 1 & $10.0 \%$ \\
\hline 2 & $17.9 \%$ \\
\hline 3 & $23.6 \%$ \\
\hline 4 & $29.0 \%$ \\
\hline 5 & $40.9 \%$ \\
\hline 6 & $50.5 \%$ \\
\hline
\end{tabular}


The initial step in this treatment decision requires a choice in medication. Aspirin has a relatively low risk of bleeding (5.58 events per 1000 patientyears), and current ACC/AHA guidelines recommend that patients in low risk categories be treated with antiplatelet aspirin therapy. ${ }^{4}$ As the patient's risk of stroke increases, anticoagulation becomes more beneficial. However, the patient's risk and benefit with anticoagulation must be weighed prior to making a final decision with the patient.The $\mathrm{CHA}_{2} \mathrm{DS}_{2}$-VASc can evaluate stroke risk, and the HAS-BLED calculator can evaluate the risk of major bleeding (Table 4). The risk of a major bleed in the HAS-BLED categories ranges from $1.13 \%$ to $12.50 \%$ per year (Table 5 ). ${ }^{5} \mathrm{~A}$ consideration relevant to major bleeds in patients on oral anticoagulants is falls. However, a prospective study of 515 patients with $60 \%$ at a high risk for falls showed no significant increased incidence of bleeding in this group, and only three patients developed nonfatal subdural hematomas. A modeling study has also demonstrated that a patient would have to fall 295 times per year to outweigh the benefit of stroke prevention in patients on anticoagulation for atrial fibrillation. ${ }^{6}$

Table 4. HAS-BLED Score

\begin{tabular}{|c|l|l|}
\hline Letter & Clinical Characteristic & Points \\
\hline H & Hypertension & 1 \\
\hline A & $\begin{array}{l}\text { Abnormal renal and } \\
\text { liver function }\end{array}$ & 1 or 2 \\
\hline S & Stroke & 1 \\
\hline B & Bleeding & 1 \\
\hline L & Labile INRs & 1 \\
\hline E & Elderly $(>65)$ & 1 \\
\hline D & Drugs of Alcohol & 1 or 2 \\
\hline
\end{tabular}

Table 5. HAS-BLED Bleeding risk

\begin{tabular}{|c|c|}
\hline Points & Annual Adjusted bleeding rate \\
\hline 0 & $1.13 \%$ \\
\hline 1 & $1.02 \%$ \\
\hline 2 & $1.88 \%$ \\
\hline 3 & $3.74 \%$ \\
\hline 4 & $8.70 \%$ \\
\hline 5 & $12.50 \%$ \\
\hline
\end{tabular}

The standard and only oral anticoagulant for many years was warfarin, but recently newer medications have emerged that add other options for the management of atrial fibrillation. These newer medications do not require strict blood work monitoring, and there is little interaction with other medications and diet. Dabigatran (Pradaxa, a direct thrombin inhibitor) was the first approved. The RE-LY (Randomized Evaluation of Long-term Anticoagulation Therapy) study reported a stroke event rate of $1.11 \%$ with $150 \mathrm{mg}$ dabigatran twice daily compared to $1.69 \%$ with warfarin. This medication had a similar bleeding risk of $3.11 \%$ compared to warfarin's $3.66 \%$ and the added benefit of not requiring blood work monitoring. This simple twice daily medication has increased compliance and ultimately eliminated the problem of supra-therapeutic and sub-therapeutic complications often seen with warfarin therapy. However, dabigatran was found to have an unexplained increased risk of $\mathrm{MI}$ and is not suitable for patients with a decreased kidney function due to renal excretion. In 2011 the ROCKET AF (Rivaroxaban Once-daily oral Direct Factor Xa Inhibition Compared with Vitamin K Antagonism for Prevention of Stroke and Embolism Trial in Atrial Fibrillation) trial compared rivaroxaban (Xarelto, a direct factor Xa inhibitor) to warfarin and found no inferiority. ${ }^{8}$ The added advantage of this medication is once daily dosing. However, the INR in the study patients was in the therapeutic range only $55 \%$ of the time and was lower than most studies (60-65\%) with 
warfarin. This factor may have shifted the results to favor rivaroxaban. In addition, post study analysis of the trial found a negative intention to treat outcome. The ARISTOTLE (Apixaban for Reduction in Stroke and Other Thromboembolic Events in Atrial Fibrillation) trial published in 2012 had decreased mortality and reduced risk of bleeding in patients treated with apixaban (Eliquis, a direct factor $\mathrm{Xa}$ inhibitor), including patients older than 75 , when compared to warfarin. ${ }^{9}$ This drug is predominantly metabolized by the liver and requires little adjustment in patients with moderate renal dysfunction. Medications on the horizon, such as Edoxaban (also a direct Factor $\mathrm{Xa}$ inhibitor) which is currently being reviewed for approval by the FDA, will offer more options for anticoagulation in the future.

Atrial fibrillation is a very common disease in the US, and treatment for stroke prevention has undergone drastic changes. Simple risk calculators have been developed to estimate the yearly risk of stroke and bleeding on anticoagulation, but ultimately any decision about anticoagulation is a patient-physician choice. Many factors contribute to this decision, including compliance and the risk of falls. However, newer medications have reduced compliance problems compared to the previously widely used warfarin. Also, the risk of falls has been shown not to significantly increase the risk of a major bleed. Ultimately, the patient and physician must decide about the treatment of atrial fibrillation, but newer risk calculators and medications can help guide the decision and inform the discussion.

\section{KEYPOINTS}

1. Thromboembolic events occur frequently in patients with atrial fibrillation.

2. Anticoagulation can reduce the event rate but increases the risk of bleeding.

3. Scoring tools, such as $\mathrm{CHA}_{2} \mathrm{DS}_{2}$-VASc and HAS-BLED, can help calculate the risk- benefit for anticoagulation.

4. This decision requires discussion and regular review with the patient. Decisions should be based on preference, clinical status, and risk assessment.

Author Affiliation: Colbert Perez is a resident in Internal Medicine at TTUHSC in Lubbock, TX. Alejandro PerezVerdia is a cardiologist in the Department of Internal Medicine at TTUHSC in Lubbock, TX.

Received: 02/02/2014

Accepted: 04/06/2014

Reviewers: Scott Shurmur MD

Published electronically: 04/15/2014

Conflict of Interest Disclosures: None

\section{REFERENCES}

1. Wann L, Curtis A, January C, et al. 2011 ACCF/AHA/HRS Focused Update on the Management of Patients With Atrial Fibrillation (Updating the 2006 Guideline): A Report of the American College of Cardiology Foundation/American Heart Association Task Force on Practice Guidelines. J Am Coll Cardiol. 2011; 57(2): 223-242.

2. Andersen L, Vestergaard P, Deichgraeber P, et al. Warfarin for the prevention of systemic embolism in patients with nonvalvular atrial fibrillation: a meta-analysis. Heart 2008; 94(12): 1607-1613.

3. Agarwal S, Hachamovitch R, Menon V. Current Trial-Associated Outcomes With Warfarin in Prevention of Stroke in Patients With Nonvalvular Atrial Fibrillation: A Meta-analysis. Arch Intern Med. 2012; 172(8): 623-631.

4. De Berardis G, Lucisano G, D'Ettorre A, et al. Association of Aspirin Use With Major Bleeding in Patients With and Without Diabetes. JAMA 2012; 307(21): 2286-2294.

5. Apostolakis S, Lane DA, Guo Y, et al. Performance of the HEMORR2HAGES, ATRIA, and HAS-BLED Bleeding RiskPrediction Scores in Patients With Atrial Fibrillation Undergoing Anticoagulation. J Am Coll Cardiol. 2012; 60(9): 861-867.

6. Man-Son-Hing M, Nichol G, Lau A, et al. Choosing antithrombotic therapy for elderly patients with atrial fibrillation who are at risk for falls. Arch Intern Med 1999; 159: 677-85.

7. Connolly S, Ezekowitz M, Yusuf PS, et al. Dabigatran versus warfarin in patients with atrial fibrillation. New Engl J Med 2009; 361(10): 1139-1151 
8. Patel MR, Mahaffey K, Garg J, et al. Rivaroxaban versus Warfarin in Nonvalvular Atrial Fibrillation. N Engl J Med 2011; 365(12): 883-891.

9. Granger CB, Alexander J, McMurray J, et al. Apixaban versus Warfarin in Patients with Atrial Fibrillation. N Engl J Med 2011; 365(12): 981-99.

10. Dentali F, Riva N, Crowther M, et al. Efficacy and safety of the novel oral anticoagulants in atrial fibrillation: a systematic review and meta-analysis of the literature. Circulation 2012; 126(20): 2381-2391. 